\title{
A Strain of Bacillus circulans Capable of Growing under Highly Alkaline Conditions
}

\author{
By MARGARE'T E. CHISLETT \\ Department of Microbiology, University of Reading, England \\ AND D. J. KUSHNER \\ Forest Insect Laboratory, Sault Ste, Marie, Ontario, Canada
}

(Received 23 July 1960)

\begin{abstract}
SUMMARY
An organism capable of growing at $\mathrm{pH}$ values up to $11 \cdot 0$ appeared, presumably as a contaminant, in the course of 'training' experiments designed to produce alkaliresistant strains of Bacillus cereus Frankland \& Frankland; this organism has now been characterized as $B$. circulans Jordan. Of 26 other strains of $B$. circulans studied, none grew at $\mathrm{pH}$ 10.7. The alkali-resistant $B$. circulans strain showed little loss of resistance after many transfers on neutral medium. When it grew in alkaline media it lowered the $\mathrm{pH}$ value of these media.
\end{abstract}

\section{INTRODUCTION}

It was reported previously (Kushner \& Lisson, 1959) that strains of Bacillus cereus Frankland \& Frankland, an organism that will not normally grow above pH 9.5, could be 'trained' by successive subcultures in media of gradually increasing $\mathrm{pH}$ value to grow at $\mathrm{pH} \mathbf{1 0 \cdot 3}$. The training process was a long one, requiring more than 50 transfers during more than a month. In four experiments it was not possible to make $B$. cereus grow at $\mathrm{pH}$ values higher than $10 \cdot 8$, even when it was transferred daily in media of this $\mathrm{pH}$ value for an additional month. In one experiment, however, the culture, which had been slowly trained to grow at $\mathrm{pH} 10.0$ took on, in five transfers, the ability to grow at $\mathrm{pH} 11 \cdot 0$. Bacteria removed when the culture had acquired the ability to grow at $\mathrm{pH} 10.0$ appeared, microscopically and in colonial form, like the alkali-resistant $B$. cereus described by Kushner \& Lisson (1959). Those removed after the culture grew at $\mathrm{pH} 10 \cdot 7$ and subcultured on neutral or alkaline buffered agar, however, were quite distinct from $B$. cereus in that the rods were thinner than those of $B$. cereus and, on agar, formed small translucent colonies. This organism has now been kept for more than 2 years by transfer on neutral or alkaline buffered nutrient agar. It is not considered likely that it was derived from $B$. cereus, but it is thought to be a contaminant which entered during the training procedure. Because of its ability to grow under highly alkaline conditions, it was further investigated.

\section{METHODS}

The conditions of growth for the experiments reported in Fig. 1 were those described earlier (Kushner \& Lisson, 1959). Phosphate-buffered nutrient broth

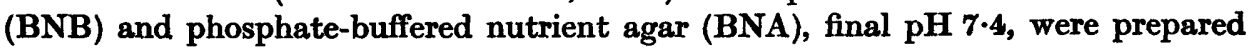


by dissolving dried nutrient broth and dried nutrient agar (Difco) in $0.1 \mathrm{~m}$ phosphate

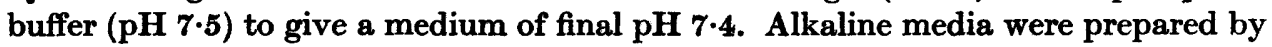
the addition of sterile $\mathrm{N}-\mathrm{NaOH}$, according to previously determined titration curves. For examining this organism, the methods and media used were similar to those of Smith, Gordon \& Clark (1952) and Knight \& Proom (1950). Tests were made on BNA ( $\mathrm{pH} 7 \cdot 4$ and $10 \cdot 7$ ); BNB ( $\mathrm{pH} 7 \cdot 4$ and 10.7); in routine laboratory media ( $\mathrm{pH} \mathrm{7.0)}$; in media made up in $0.1 \mathrm{M}$-phosphate buffer ( $\mathrm{pH} \mathrm{7.5)}$. Incubation was at $37^{\circ}$, except where otherwise stated.

Spore sculpture. The surface configuration of spores was kindly examined for us by Mr D. E. Bradley by the electron microscope and the carbon replica method of Bradley \& Williams (1957).

\section{RESULTS}

Morphological characters of the highly alkali-resistant organism

The organism conforms in all respects to the description of Bacillus circulans given by Smith et al. (1952). No difference was found in the morphology on BNA (pH 7.4) and nutrient agar (pH 7.0). On BNA (pH 10.7) at $24 \mathrm{hr}$. the rods were slightly thinner and longer than on BNA ( $\mathrm{pH} 7 \cdot 4)$. The swollen sporangia and oval spores were similar to those formed on BNA ( $\mathrm{pH} 7 \cdot 4)$.

Spore sculpture. The sculpture of the spore surface was found by Mr D. E. Bradley by using the electron microscope and carbon replica method of Bradley \& Williams (1957) to be smooth.

\section{Growth characters}

No difference was obtained from the description of Bacillus circulans by Smith et al. (1952) apart from the inability to grow anaerobically. No growth was obtained on the surface of nutrient agar and BNA + glucose $(1 \%, w / v)$ slopes or streak plates in McIntosh and Fildes jar (aerobic controls positive), and surface growth only in BNA and nutrient agar + glucose $(1 \%, w / v)$ shake tubes. The organism appears therefore to be an obligate aerobe. Colonial form and amount of growth appeared similar on BNA (pH 7.4) and BNA (pH 10.7).

\section{Physiological characters}

The organism conforms to the description of Bacillus circulans by Smith et al. (1952) apart from the inability to produce acid from glucose. No growth was obtained on inorganic salts basal medium + sugar up to 7 days at $30^{\circ}$ or $37^{\circ}$. Growth but no acid was obtained on nutrient agar slopes with bromcresol purple indicator + glucose, xylose, arabinose, sucrose, mannitol, maltose or raffinose after 7-14 days at $30^{\circ}$ or $37^{\circ}$.

Nutrition. The nutritional requirements of this organism were satisfied by a medium containing salts, acid-hydrolysed casein (Knight \& Proom, 1950) thiamine and biotin. An ammonia basal medium (Knight \& Proom, 1950) did not replace the casein basal medium.

\section{Examination of strains of Bacillus circulans for alkali resistance}

The above "evidence indicated that this organism could be classified as a strain of Bacillus circulans Jordan. A collection of 26 strains of B. circulans from different sources was therefore examined to assess the occurrence of alkali resistance in this 
species. Fourteen strains from the Wellcome Research Laboratory collection (Knight \& Proom, 1950) and 12 isolated from soil (by M.E.C.) were tested for ability to grow in alkaline media. The cultures were maintained routinely on nutrient agar (pH 7.0) and were subcultured several times in $\mathrm{BNB}(\mathrm{pH} 7 \cdot 4)$ at $30^{\circ}$ and $37^{\circ}$ before testing.

Cultures (24 hr.) in BNB (pH 7.4) at $30^{\circ}$ and $37^{\circ}$ were inoculated by adding two $4 \mathrm{~mm}$. loopfuls to $\mathrm{BNB}$ at $\mathrm{pH} \% \cdot 4$ and 10.7. Alkali resistance was indicated by

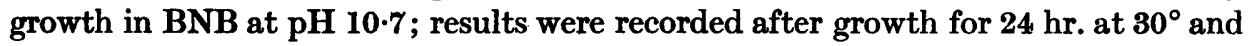
$37^{\circ}$. None of the 26 strains tested grew in BNB at pH 10.7 in 24 hr.; with the exception of one strain (CN 3378), all grew within $24 \mathrm{hr}$. in BNB at pH $7 \cdot 4$.
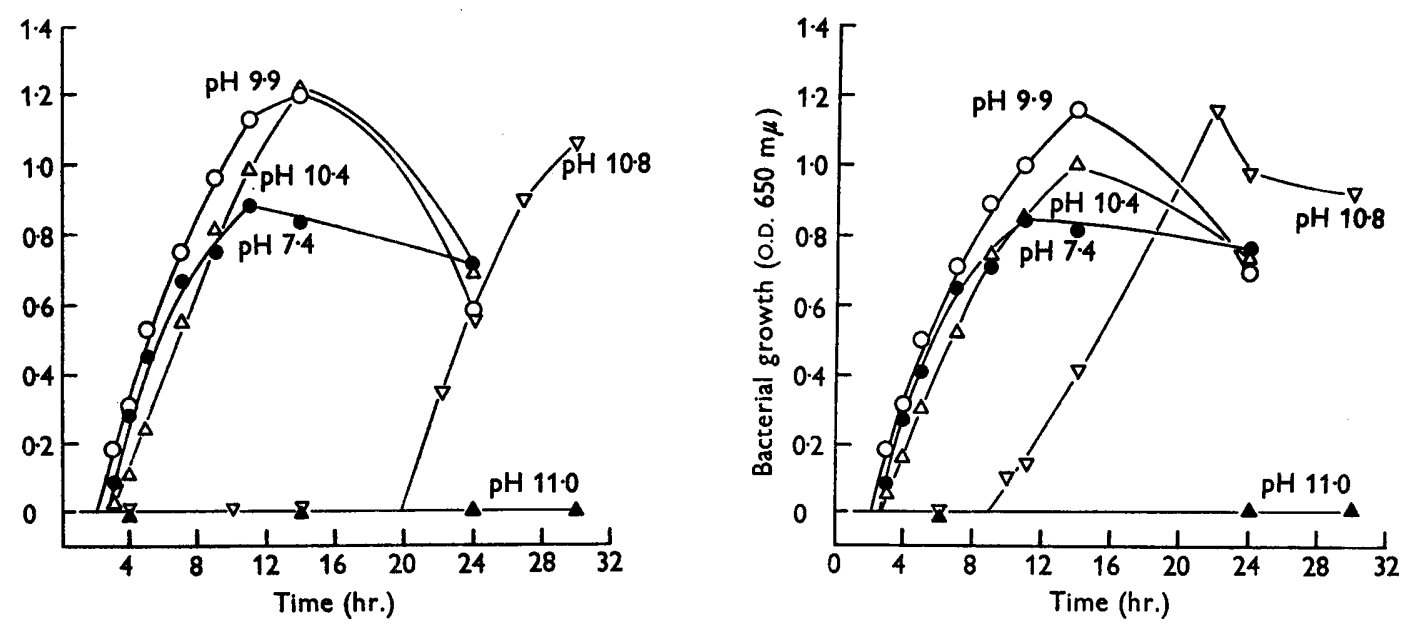

Fig. $1 a, b$. The effect of pH value on growth of alkali-tolerant Bacillus circulans. $a$, Bacteria maintained for 1 year at $\mathrm{pH} 7 \cdot 4 ; b$, bacteria maintained for 1 year at $\mathrm{pH} 10 \cdot 7$. Bacteria were grown for $20 \mathrm{hr}$. on BNA of $\mathrm{pH} 7 \cdot 4(a)$ or $10.7(b)$, resuspended in BNB (pH 7.4) and an inoculum equiv. $0.025 \mathrm{mg}$. dry wt. bacteria in $0.3-0.5 \mathrm{ml}$. broth added to tubes containing $10 \mathrm{ml}$. BNB of the pH values shown. Incubation, shaking, and measurement of optical density were as described by Kushner \& Lisson (1959).

\section{Growth at different $\mathrm{pH}$ values and the retention of alkali tolerance}

The effect of the pH value of the medium on the growth of this organism in BNB is shown in Fig. 1. Comparison was made between bacteria which had been maintained for 1 year on BNA ( $\mathrm{pH} 7 \cdot 4$ ) with transfers at 2-week intervals (Fig. 1a) and bacteria which had been similarly maintained at $\mathrm{pH} 10 \cdot 7$ (Fig. $1 b$ ). Both cultures grew after a slightly shorter lag period at $\mathrm{pH} 9.9$ than at $\mathrm{pH} \mathrm{7 \cdot 4}$. In the highly alkaline media in which growth occurred, cultures reached a higher density than

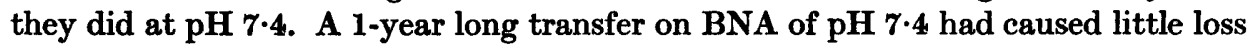

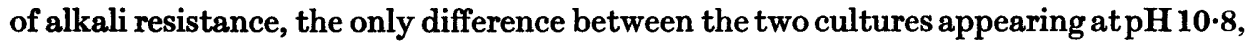
where the bacteria maintained at $\mathrm{pH} 7 \cdot 4$ grew after a lag period $11 \mathrm{hr}$. longer than did those maintained at pH 10.7. When first isolated, these bacteria grew in shaken cultures of $\mathrm{pH} \mathrm{11 \cdot 0.} \mathrm{Two} \mathrm{years} \mathrm{later,} \mathrm{at} \mathrm{the} \mathrm{time} \mathrm{of} \mathrm{the} \mathrm{experiment} \mathrm{shown} \mathrm{in} \mathrm{Fig.} \mathrm{1,}$ they still grew on BNA at $\mathrm{pH} 11.0$ but did not grow in shaken BNB of this $\mathrm{pH}$ value. In this, they resemble alkali-resistant B. cereus (Kushner \& Lisson, 1959), which grew at a slightly higher $\mathrm{pH}$ value on agar than in liquid medium. 
In the late stages of incubation with shaking, there was a decrease in the optical density of all cultures. No clumping of the bacteria was observed, and the culture became viscous, indicating that lysis was probably taking place. As with alkaliresistant Bacillus cereus, the growth of the present organism in alkaline media lowered the $\mathrm{pH}$ value. After incubation for $30 \mathrm{hr}$. the $\mathrm{pH}$ value of the culture which was originally at $7 \cdot 4$ had increased to $7 \cdot 8$, and the $\mathrm{pH}$ values of all other cultures had decreased to $8 \cdot 8-9 \cdot 0$.

\section{DISCUSSION}

The swollen sporangia and oval spores produced by this alkali-resistant organism indicate that it is a Bacillus sp. of morphological group 2 (Smith et al. 1952). The results of the physiological tests classify the organism as a strain of Bacillus circulans. Inability to produce acid from glucose and to grow anaerobically is, however, not typical of $B$. circulans, although atypical reactions of this kind are not uncommon with strains of this species-complex. The smooth surface sculpture of the spores is similar to that found in some strains of $B$. circulans, although other strains of this species may show longitudinal parallel ribs or reticulation (Bradley \& Franklin, 1958). The nutritional requirements of this strain are also consistent with those found by Knight \& Proom (1950) for some strains of $B$. circulans and for Bacillus species in general. Since alkali resistance was not found in 25 other strains of $B$. circulans the high resistance shown by this particular strain is, thus far, unique.

The alkali-resistant Bacillus circulans strain has been sent to the National Collection of Industrial Bacteria, Torry Research Station, Aberdeen.

We are indebted to Mr D. E. Bradley (A.E.I. Research Laboratories, Aldermaston Court, Berkshire) for the examination of the spore sculpture by the carbon replica method, and to Professor B. C. J. G. Knight for advice during part of this investigation. Mr T. A. Lisson provided valuable technical assistance during the early stages of this work. This paper is contribution no. 658, Forest Biology Division, Research Branch, Department of Agriculture, Ottawa, Canada.

\section{REFERENCES}

Bradley, D. E. \& Frankin, J. G. (1958). Electron microscope survey of the surface configuration of spores of the genus Bacillus. J. Bact. 76, 618 .

Bradley, D. E. \& Wrulams, D. J. (1957). An electron microscope study of the spores of some species of the genus Bacillus using carbon replicas. J. gen. Microbiol. 17,75 .

Knight, B. C. J. G. \& Proom, H. (1950). A comparative study of the nutrition and physiology of mesophilic species in the genus Bacillus. J. gen. Microbiol. 4, 508.

Kushner, D. J. \& Lrsson, T. A. (1959). Alkali resistance in a strain of Bacillus cereus pathogenic for the larch sawfly Pristiphora erichsonii. J. gen. Microbiol. $21,96$.

Smith, N. R., Gordon, R. E. \& Clark, F. E. (1952). Aerobic spore-forming bacteria. Monogr. U.S. Dep. Agric. No. 16. 